\title{
APPLICATION OF LABORATORY BETA RADIOMETRY FOR QUANTITATIVE INDICATION OF RADIONUCLIDE CONCENTRATION IN PLANT SAMPLES
}

\author{
Dmitro Ganzha, Borys Sploshnoy, Dmytro Ganzha (Jun)
}

\begin{abstract}
The aim is to improve the beta-radiometric method of quantitative indication of the content of ${ }^{90} \mathrm{Sr}$ and ${ }^{137} \mathrm{Cs}$ in the counters of plant samples.

Material and methods. In the Chernobyl exclusion zone (ChEZ) in 2017, 2019, leaves of silver birch, black poplar, common reed, sedge were selected, which were dried, crushed, and used as calculating samples for beta radiometry and spectrometry. For measurements, a combined KRK-1 radiometer and a SEB 01-150 spectrometer beta-radiation energy were used.

Results. Currently, in plant samples from the ChEZ, the following are widespread: natural ${ }^{40} \mathrm{~K}$, the concentration of which is usually less than $1 \%$ in relation to the concentration of technogenic radionuclides ${ }^{90} \mathrm{Sr}+{ }^{90} \mathrm{Y}$ and ${ }^{137} \mathrm{Cs}$, therefore, when measuring ${ }^{90} \mathrm{Sr}$ and ${ }^{137} \mathrm{Cs}$, beta radiation of ${ }^{40} \mathrm{~K}$ can be ignored. The measurements were carried out without a spectral filter and using a thin molybdenum filter. Without filter-show the count rate of ${ }^{90} \mathrm{Sr}+{ }^{90} \mathrm{Y}$ and ${ }^{137} \mathrm{Cs}$ radiation. The filter transmits 2-3.5\% of the low-energy beta radiation of ${ }^{90} \mathrm{Sr}$ and ${ }^{137} \mathrm{Cs}$ and more than $95 \%$ of the high-energy ${ }^{90} Y$. The ratio of the count rate of ${ }^{90} Y$ pulses with and without filter is 2.14 . The ${ }^{90} \mathrm{Sr}$ concentration in the samples was determined from the results of measurements of ${ }^{90} \mathrm{Y}$, and ${ }^{137} \mathrm{Cs}$ - through the fraction of the counting rate, which remains after deducting ${ }^{90} \mathrm{Sr}+{ }^{90} \mathrm{Y}$. Comparison of the concentration of radionuclides measured by the method of betaradiometry and spectrometry showed no significant difference between the results obtained by the two methods.

Conclusions. The beta radiometry method for ${ }^{90} \mathrm{Sr}$ and ${ }^{137} \mathrm{Cs}$ provides for measuring the counting rate of beta radiation from counting samples without a spectral filter and using a thin molybdenum filter. Based on the research results, a procedure for calculating the concentration of ${ }^{90} \mathrm{Sr}$ and ${ }^{137} \mathrm{Cs}$ in counting samples of plant leaves was developed
\end{abstract} Keywords: Chernobyl exclusion zone, ${ }^{90} \mathrm{Sr},{ }^{137} \mathrm{Cs}$, plants, radioecology, beta-radiometry, radiospectrometry

How to Cite:

Ganzha, D., Sploshnoy, B., Ganzha (Jun), D. (2021). Application of laboratory beta radiometry for quantitative indication of radionuclide concentration in plant samples. ScienceRise: Biological Science, 1 (26), 20-26. doi: http://doi.org/10.15587/2519-8025.2021.228646

(C) The Author(s) 2021

This is an open access article under the CC BY license (http://creativecommons.org/licenses/by/4.0).

\section{Introduction}

When conducting radioecological surveys of manmade contaminated areas, there is a need for rapid assessment of the specific activity of ${ }^{90} \mathrm{Sr}$ and ${ }^{137} \mathrm{Cs}$ in the counters of plant samples.

Laboratory beta-radiometry is considered to be the most efficient and least expensive method for such measurements. Unfortunately, the existing method involves only the measurement of the total specific activity of beta-emitting radionuclides in the drugs, which significantly narrows the possibilities of its application. To develop and improve beta-radiometry, it is important to develop procedures that allow the identification of certain radionuclides in counting samples.

\section{Literary review}

Beta-radiometry is successfully used in the indication of radionuclide contamination of the environment and in biological research. Radiometric methods that are traditional still remain unique for the detection of radionuclides with different half-lives. It is important that methods for determining radionuclides be sensitive, ac- curate, and low cost. Radiometric methods meet these requirements. The peculiarity of these methods is that they do not require large equipment or infrastructure [1].

However, by the method of beta-radiometry it is impossible to selectively determine individual radionuclides by their radiation energy. In addition, there is the problem of self-absorption of low-energy radiation by a counting sample. That is, the determination of radionuclides with low radiation energies is complicated in the presence of radionuclides with high-energy radiation. In order to overcome these problems, various methods are used to increase the sensitivity of the beta-radiometric method. For example, selective extraction of radionuclides from the sample [1], the creation of a thin-layer counting sample $[1,2]$, the use of absorbers of different thickness between the sample and the counter [1]. To simplify the measurement method and increase their expressiveness, when the energy spectrum of the radionuclide mixture of the counting sample allows, the most acceptable is the use of ionizing radiation filters (hereinafter - filters) between the counting sample and the detector. Metal filters with different equivalent radiation 
thickness are used to cut off radionuclides with lower energies and protect, for example, gamma detectors from high-energy beta radiation [1-3].

In the counting samples of vegetation there is a mixture of radionuclides of both man-made and natural origin. The largest powerful source of beta radiation among natural radionuclides is ${ }^{40} \mathrm{~K}$. In areas with a high content of natural radionuclides in the environment, the specific activity of beta-emitting radionuclides in grassy vegetation can reach significant levels, up to $1800 \pm$ $\pm 263 \mathrm{~Bq} / \mathrm{kg}$, due to both ${ }^{40} \mathrm{~K}$ and decay products of uranium and thorium [4].

\section{The purpose and objectives of the study}

The aim of the work is to improve the existing method of laboratory beta-radiometry for quantitative indication of the specific activity of radionuclides of manmade origin ${ }^{90} \mathrm{Sr}$ and ${ }^{137} \mathrm{Cs}$ in the preparations of plant origins, on the example of ChEZ.

To achieve this goal it was necessary to perform the following tasks:

1) Develop registration procedures for ${ }^{90} \mathrm{Sr}+{ }^{90} \mathrm{Y}$ and ${ }^{137} \mathrm{Cs}$, which are based on the use of a beta radiation energy filter;

2) To develop procedures for measuring counting samples of plant origin contaminated with a mixture of radionuclides $-{ }^{90} \mathrm{Sr}+{ }^{90} \mathrm{Y}$ and ${ }^{137} \mathrm{Cs}$, and processing the results of the study;

3) Evaluate the value of the relative total uncertainty of the results formed during the quantitative betaradiometric indication, and compare the results with the data of beta-spectrometric measurements of ${ }^{90} \mathrm{Sr}$ and ${ }^{137} \mathrm{Cs}$ in counting samples of plant origin.

\section{Materials and methods}

The research was conducted in 2017-2019. The leaves of silver birch (Betula pendula Roth.), ulack poplar (Populus nigra L.), common reed (Phragmites australis (Cav.) Trin. Ex Steud) and sedge (Carex acuta) were used for observations, which were collected in the Chornobyl Exclusion Zone in the ecosystems of Azbuchyn, Hlyboke and Daleke lakes, the Chernobyl station cooler reservoir, the Yaniv Bay of the Pripyat River near the city of Pripyat, and the Pripyat River in the vicinity of Chornobyl city. Samples from the last of these ecosystems were considered to be collected in the context of local radionuclide contamination. At least 30 leaves from different plants at each site were selected for the study.

The preparations were air-dried, ground and sent as beta-samples for beta-radiometric and betaspectrometric analysis. The rate of counting beta particles emitted by counting samples of plant leaves was measured using a radiometer combined KRK-1 (Russia). Measurements of the pulse counting rate from beta particles, calculation of the radiometric background and the number of registered pulses were performed according to the existing technical documentation [5]. The relative uncertainty in laboratory beta radiometry did not exceed $30 \%$. Beta-radiometry of the drugs was performed without a filter and with a radiospectrometric filter made of thin molybdenum (density $-10.22 \mathrm{~g} / \mathrm{cm}^{3}$ ) with a thickness of $0.11 \mathrm{~mm}$.
Measurements of some samples of reed plants collected in 2017 were performed on ${ }^{90} \mathrm{Sr}$ and ${ }^{137} \mathrm{Cs}$ by spectrometry, using a beta-radiation spectrometer SEB 01-150 (Ukraine) in the laboratory "DSP Ecocenter". Uncertainty in ${ }^{90} \mathrm{Sr}$ beta spectrometry did not exceed $18 \%,{ }^{137} \mathrm{Cs}-15 \%$.

The relative measurement uncertainty was calculated according to existing recommendations (JCGM 100: 2008, 2008) as the standard deviation of several consecutive measurements of one sample.

$$
u, \%=\frac{\sqrt{\sum u_{c}^{2}}}{\bar{x}} \cdot 100
$$

where $u_{c}^{2}$ - standard deviation of parameters when calculating uncertainty; $x$ is the average value of the measured parameters.

Statistical analysis of measurement results by the Monte Carlo method was performed using the software application Past 3.19. The Monte Carlo permutation test [6] was used to accurately estimate the probability of the following statistical parameters. The Monte Carlo method is based on 99,999 random reassignments of values in a column within each pair and is displayed as probability $(p)$. Spearman's correlation coefficient $(r S)$ was used to estimate the relationship of the sample pairs. The closer $p$ is to 0 , the more likely it is that there is no significant difference between the samples being compared. When performing the analysis, the value is taken that $p>0.5$ means no correlation. The Mann-Whitney (MW) test was used to compare the medians of the two samples. The null hypothesis of this test is: two samples are taken from populations with equal medians. The hypothesis is confirmed when $p>0.5$. The KolmogorovSmirnov (KS) criterion was used to compare the type of statistical distribution of the two samples. The null hypothesis is: two samples are taken from populations with the same distribution. The null hypothesis is rejected if the value of the statistics $D>p$.

The samples were checked for similarity of correlation coefficients (CV) using the Fligner-Killeen test. Null hypothesis: samples were taken from populations with the same coefficient of variation. The null hypothesis is rejected if $p<0.05$.

\section{Research results and their discussion}

5. $1 .{ }^{90} \mathrm{Sr}+{ }^{90} \mathrm{Y}$ and ${ }^{137} \mathrm{Cs}$ registration procedures based on the use of a beta radiation filter

The average potassium content in the leaves of reed - plants with high ash content, selected in ChEZ, is $940 \pm 300 \mathrm{mg} / \mathrm{kg}$, respectively ${ }^{40} \mathrm{~K} 30 \pm 10 \mathrm{~Bq} / \mathrm{kg}$ [4]. The leaves of ChEZ plants contain 4 beta emitting radionuclides: natural $-{ }^{40} \mathrm{~K}$, man-made $-{ }^{90} \mathrm{Sr}+90 \mathrm{Y}$, and ${ }^{137} \mathrm{Cs}$. According to the results of numerical measurements, in most counting samples of plants taken in ChEZ, the concentration of ${ }^{40} \mathrm{~K}$ is usually less than $1 \%$, and in the local background of radionuclide contamination - up to $5 \%$ relative to the concentration of man-made radionuclides $[7,8]$, therefore, when measuring ${ }^{90} \mathrm{Sr}$ and ${ }^{137} \mathrm{Cs}$ with ${ }^{40} \mathrm{~K}$ beta radiation, it can be neglected. Thus, when measuring beta-emitting radionuclides in the vegetative mass of plants, technogenic ${ }^{90} \mathrm{Sr}$ and ${ }^{137} \mathrm{Cs}$ are significant 
today. The concentration of these radionuclides, for example in higher aquatic plants, which are the most contaminated under ChEZ conditions, varies by ${ }^{90} \mathrm{Sr}$ from $60 \mathrm{~Bq} / \mathrm{kg}$ to $8500 \mathrm{~Bq} / \mathrm{kg}$ and for ${ }^{137} \mathrm{Cs}$ from $200 \mathrm{~Bq} / \mathrm{kg}$ to $20,000 \mathrm{~Bq} / \mathrm{kg}$, at high values of coefficients of variation of specific activity for both radionuclides, ranging from $60 \%$ to $200 \%$ [7, 8]. Required methods of separation of technogenic radionuclides from natural ones. The given data show that in ChEZ conditions, where plants are characterized by low concentration of natural radionuclides and extremely high pollution - technogenic, for selective quantitative beta-radiometry of ${ }^{90} \mathrm{Sr}$ and ${ }^{137} \mathrm{Cs}$ it is important to use filters.
It is known to use for the separation of radionuclides with lower energies filters made of non-ferrous metals and alloys, such as brass [2]. To cut off lowenergy radiation ${ }^{90} \mathrm{Sr}$ and ${ }^{137} \mathrm{Cs}$ with maximum energy values $(\mathrm{MeV})-0.54$ and 0.52 , respectively [9], we used a molybdenum filter. It has been experimentally established on the example of ${ }^{137} \mathrm{Cs}$ that the applied filter almost completely cuts off the beta radiation of plant sources of contaminated ${ }^{90} \mathrm{Sr}$ and ${ }^{137} \mathrm{Cs}$ with a specific activity that occurs in the territory of ChEZ during the last 10 years [10]. Radiation of directly ${ }^{137} \mathrm{Cs}$ is reliably recorded by laboratory beta radiometry, even at low activities and low-density cellulose matrix (Table 1).

Table 1

The results of measuring the rate of calculation of IRS of different densities of ${ }^{137} \mathrm{Cs}$ beta radiation sources

\begin{tabular}{|l|c|c|c|c|c|c|}
\hline \multicolumn{1}{|c|}{ Type of IRS } & Density, $\mathrm{g} / \mathrm{cm}^{3}$ & $\mathrm{~A}, \mathrm{~Bq} / \mathrm{kg} \Gamma$ & $\mathrm{n}$ & $\mathrm{Imp} / \mathrm{s}$ & Measured activity & $\mathrm{K}_{\mathrm{Mo}}, \%$ \\
\hline TSMP-1 & 1 & 3095 & 3 & 0.19 & 3040 & $2.1 \pm 1.0$ \\
\hline BS $\left({ }^{137} \mathrm{Cs}\right)$ & 0.01 & 17052 & 5 & 1.15 & 17052 & $3.3 \pm 1.5$ \\
\hline
\end{tabular}

Note: $\mathrm{A}, \mathrm{Bq} / \mathrm{kg}$-IRS activity; $n$ is the number of measurements, $B S\left({ }^{[37} \mathrm{Cs}\right)$ - bulk source of beta radiation with a matrix of cellulose; $K_{M o}$ - the ratio of the rate of calculation of beta radiation passing through the molybdenum filter, relative to the original activity, TSMP-1 - three-dimensional source with a matrix of polymer resin.

From the Table 1 shows that the molybdenum filter passes from $2 \%$ to $3.5 \%$ of beta particles emitted by ${ }^{137} \mathrm{Cs}$ in the counting sample. This parameter was calculated as the protection factor for low-energy radiation $\left(K_{\mathrm{le}}\right)$ on the example of standard IRS ${ }^{137} \mathrm{Cs}$, according to the formula:

$$
K_{\mathrm{le}}=I_{\mathrm{Mo}}(\mathrm{Cs}) \cdot I_{\mathrm{imp} / \mathrm{s}}^{-1}(\mathrm{Cs}),
$$

where $I_{\mathrm{imp} / \mathrm{s}}$ - pulse counting speed from the IRS (with subtracted background); $I_{\mathrm{Mo}}$ - the speed of counting the pulses registered using a molybdenum filter (with the background subtracted). The background counting speed was measured and calculated according to the technical documentation of the radiometer [5].

The $K_{l e}$ value is established on the basis of multiple measurements of ${ }^{137} \mathrm{Cs}$ analytical standards, within this work is equal to 0.033 and is used in calculations as a constant. Given the proximity of the maximum radiation energy of ${ }^{90} \mathrm{Sr}$ and ${ }^{137} \mathrm{Cs}$, the result obtained can also be attributed to ${ }^{90} \mathrm{Sr}$ radiation. Given that the maximum energy of beta radiation ${ }^{90} \mathrm{Y}-2.28 \mathrm{MeV}$ [9], we can assume that the applied molybdenum filter transmits mainly ${ }^{90} \mathrm{Y}$ radiation.

The effectiveness of protecting a molybdenum filter from beta radiation from counting samples has been empirically established. Radiation sources $\left({ }^{90} \mathrm{Sr}+{ }^{90} \mathrm{Y}\right)$ with activity from $50 \mathrm{~Bq}$ to $11100 \mathrm{~Bq}$ were used as counting samples (Table 2).

The measurements show that when using IRS that differ by several orders of magnitude, the value of the protection factor varies within the statistical error. Accordingly, within all possible values of the specific activity of the counting vegetation samples that can occur in ChEZ, when using a molybdenum filter, only highenergy radiation ${ }^{90} \mathrm{Y}$ is measured.

Table 2

The efficiency of protection of the molybdenum filter when using beta-emitting sources ${ }^{90} \mathrm{Sr}+{ }^{90} \mathrm{Y}$ of different activity and geometry (measurement was performed with an average uncertainty of $27 \%$ )

\begin{tabular}{|c|c|c|c|c|c|}
\hline Type of IRS & $\mathrm{Bq} / \mathrm{cm}^{2}$ & $\mathrm{~N}$ & $\mathrm{imp} / \mathrm{s}$ & $\mathrm{imp} / \mathrm{s}(\mathrm{Mo})$ & $\mathrm{K}$ protection \\
\hline $\mathrm{BS}\left({ }^{90} \mathrm{Sr}+{ }^{90} \mathrm{Y}\right)$ & 1.3 & 20 & 4.3 & 1.5 & 2.9 \\
\hline $4 \mathrm{CO}-212$ & 2.7 & 5 & 11 & 3.5 & 3.1 \\
\hline $4 \mathrm{CO}-802$ & 8.6 & 5 & 36 & 11.3 & 3.2 \\
\hline $4 \mathrm{CO}-213$ & 28.2 & 5 & 116 & 35.3 & 3.3 \\
\hline $4 \mathrm{CO}-803$ & 93.6 & 5 & 365 & 118 & 3.1 \\
\hline $4 \mathrm{CO}-214$ & 252.6 & 5 & 848 & 304 & 2.8 \\
\hline
\end{tabular}

Note: 4CO - planar sources of beta radiation, Mo - molybdenum filter located between the IRS and the radiometer detector, $n-$ number of measurements, $B S\left({ }^{90} \mathrm{Sr}+{ }^{90} \mathrm{Y}\right)$-volumetric source of beta radiation with a matrix of cellulose

When measured without a filter, the beta particle flux consists of low-energy ${ }^{90} \mathrm{Sr}$ radiation and highenergy ${ }^{90} \mathrm{Y}$ radiation (Table 2 ).

In order to take into account the difference in the efficiency of pulse recording from high $\left(E_{\mathrm{he}}\right)$ and lowenergy $\left(E_{\mathrm{le}}\right)$ radiation, the values of relative units of registration efficiency given in the technical documentation to the laboratory beta radiometer KRK-1 were used. The calculated ${ }^{90} \mathrm{Sr},{ }^{90} \mathrm{Y}$ and ${ }^{137} \mathrm{Cs}$ fractions were multiplied by correction factors of $0.46,0.95$ and 0.44 , respectively [5].

Calculation of the proportion of beta radiation ${ }^{90} \mathrm{Y}$ in standard samples of IRS was performed by the formula:

$$
I_{\mathrm{he}}=E_{\mathrm{ihe}} \cdot I_{\mathrm{imp} / \mathrm{s}} \cdot\left(E_{\mathrm{he}}+E_{\mathrm{le}}\right)^{-1}
$$

where $E_{\text {ihe }}$ - the share of registered pulses from radiation 
${ }^{90} \mathrm{Y} ; E_{\mathrm{he}}-$ the efficiency of registration of pulses of highenergy radiation, in this case ${ }^{90} \mathrm{Y}$ in relative units from 0 to 1 [5]; $E_{\mathrm{le}}$ - the efficiency of registration of pulses of low-energy radiation, in this case ${ }^{90} \mathrm{Sr}$.

To find the proportion of high-energy beta radiation recorded from experimental counting samples, the ratio of ${ }^{90} \mathrm{Y}$ pulses to pulses recorded using a molybdenum filter was calculated from the results of measurements of standard IRS samples. The calculations were performed according to the equation:

$$
K_{\mathrm{IBE}}=I_{\mathrm{BE}} \cdot I_{\mathrm{Mo}}{ }^{-1}
$$

$K_{\text {IBE }}$ calculations performed for all measured standard IRS samples (Table 2) showed that the average $K_{\mathrm{IBE}}$ value $=2.14$, with an uncertainty of $26 \%$. The share of low-energy radiation in the calculation rate from the IRS was calculated by the equation:

$$
I_{\mathrm{le}}=\left(I_{\mathrm{imp} / \mathrm{s}}-I_{\mathrm{BEY}}\right) \cdot E_{\mathrm{le}}^{-1 .}
$$

The application of correction factors equalized the values of the fractions of the rate of calculation of the measured radionuclides $\left(I_{\mathrm{E}}\right)$, and these data calculated the sensitivity of the registration of radiation IRS $\left(E_{A(r n)}\right)$ :

$$
E_{A(r n)}, \mathrm{Bq} / \mathrm{imp} .=A_{r n} \cdot I_{r n}{ }^{-1}
$$

where $A_{r n}, \mathrm{~Bq}$ - IRS activity on the corresponding radionuclide; $I_{\text {rn }}$, imp. - the fraction of the rate of calculation of the corresponding radionuclide

According to the results of calculating the efficiency of registration of IRS radiation given in Table 1 found that the average value of $E_{A}=12 \mathrm{~Bq} / \mathrm{imp}$, with uncertainty $-27 \%$.

The deviation of the measured specific activity of ${ }^{137} \mathrm{Cs}$ from that prescribed for BS and TSMP-1 is less $-1 \%$. The sensitivity of the analysis decreases by about a third as the density of the sample increases. For IRS with a matrix of $0.1 \mathrm{~g} / \mathrm{cm}^{3}$, the sensitivity value calculated by formula 5 is $26 \mathrm{~Bq} / \mathrm{imp}$, and for IRS with a density of $1 \mathrm{~g} / \mathrm{cm}^{3}-36 \mathrm{~Bq} / \mathrm{imp}$.

Accordingly, for the method of radiometric indication of ${ }^{90} \mathrm{Sr}$ and ${ }^{137} \mathrm{Cs}$ in samples of vegetative mass of plants with low density, which differ from denser samples of wood, forest litter, and soil, the values of $E_{a}=21.4 \mathrm{~Bq} / \mathrm{imp}$.

The proposed method of laboratory radiometric measurement of high-energy and low-energy radionuclides using a molybdenum filter showed that it makes it possible to estimate the proportions of recorded pulses generated by radiation with different energy from different radionuclides. The calculated ratio of the pulses ${ }^{90} \mathrm{Y}$ to the pulses recorded using the molybdenum filter must be recalculated when changing the radiometer, or changing the filter, or when performing metrological verification. The value of the coefficient must also be checked and clarified at each subsequent calibration of the measuring equipment. The efficiency coefficient of IRS radiation registration for ${ }^{90} \mathrm{Sr}+{ }^{90} \mathrm{Y}$ is also established, which allows to calculate the activity of the radionuclide in the radiation source based on the results of the adjusted pulse counting calculation. In the case of a pulse ratio of ${ }^{90} \mathrm{Y}$ to pulses recorded using a filter, this ratio must also be specified for each individual measuring instrument and during their verification.

Thus, it is possible to determine the activity of ${ }^{90} \mathrm{Y}$ in the counting sample by taking into account the difference in the efficiency of recording pulses from high and low energy radiation when using a filter. The method allows to determine ${ }^{90} \mathrm{Sr}$ and ${ }^{90} \mathrm{Y}$ with a relative uncertainty of not more than $30 \%$.

The method is based on an empirically established coefficient. The molybdenum filter used transmits from $2 \%$ to $3.5 \%$ of low-energy beta particles emitted by ${ }^{137} \mathrm{Cs}$ in the counting sample. Given the proximity of the maximum radiation energy of ${ }^{90} \mathrm{Sr}$ and ${ }^{137} \mathrm{Cs}$, the result obtained can also be attributed to ${ }^{90} \mathrm{Sr}$ radiation.

\section{2. Procedure for measuring counting sam-} ples of plant origin contaminated with a mixture of radionuclides $-{ }^{90} \mathrm{Sr}+{ }^{90} \mathrm{Y}$ and ${ }^{137} \mathrm{Cs}$ and calculating the results of the study

The main beta contaminating radionuclides $-{ }^{90} \mathrm{Sr}$ and ${ }^{137} \mathrm{Cs}$ are always found together in vegetation samples with ChEZ, although in different proportions. Due to the high energy beta radiation of ${ }^{90} \mathrm{Y}$, direct measurement of ${ }^{90} \mathrm{Sr}$ and ${ }^{137} \mathrm{Cs}$ using laboratory beta radiometry is not possible, but the specific activity of ${ }^{90} \mathrm{Sr}$ in the counting samples can be calculated from the measurement results of ${ }^{90} \mathrm{Y}$. The concentration of ${ }^{137} \mathrm{Cs}$ is calculated as a fraction of the counting rate, minus ${ }^{90} \mathrm{Sr}+{ }^{90} \mathrm{Y}$.

Conducted experiments to determine the correction for backscattering (q) from IRS ${ }^{90} \mathrm{Sr}+{ }^{90} \mathrm{Y}$ and $137 \mathrm{Cs}$ radiation showed that ${ }^{90} \mathrm{Sr}+{ }^{90} \mathrm{Y}$ give virtually no statistically significant backscattering, and ${ }^{137} \mathrm{Cs}$ backscattering averages 1.15 [2]. Accordingly, this figure was taken into account when calculating the beta radiation with low energy.

Measurements of the specific activity of ${ }^{90} \mathrm{Sr}$ and ${ }^{137} \mathrm{Cs}$ were performed in two stages: in the first - the measurement of the total rate of beta radiation counting of the counting sample was performed. The second is the measurement of the counting speed using a molybdenum filter.

The calculation was performed in 7 stages:

In the first stage, the fraction of low-energy beta radiation ${ }^{90} \mathrm{Sr}$ and ${ }^{137} \mathrm{Cs}$ transmitted by the molybdenum filter $\left(K_{\mathrm{SrCs}}\right)$ was calculated. Values $\left(K_{\mathrm{SrCs}}\right)$ were calculated by the formula

$$
K_{\mathrm{SrCs}}=I_{\mathrm{MO}} \cdot K_{\mathrm{MO}} \cdot 2
$$

In the second stage of calculations set the value of the actual efficiency of registration of the counting sample $\left(E_{\mathrm{prb}}\right)$, according to the formula:

$$
E_{\mathrm{prb}}=\left(I_{\mathrm{MO}} \cdot\left(E_{\mathrm{he}}+E_{\mathrm{le}}\right)\right) \cdot I_{\mathrm{imp} / \mathrm{s}}^{-1}
$$

In the third stage of calculations set the share of ${ }^{90} \mathrm{Y}$ in the total counting speed $\left(\mathrm{I}_{\mathrm{Y}} \mathrm{E}\right)$ by the formula:

$$
I_{\mathrm{Y}}=\left(\left(I_{\mathrm{Mo}}-K_{\mathrm{SrCs}}\right) \cdot K_{\mathrm{IBE}} \cdot E_{\mathrm{prb}}\right) \cdot E_{\mathrm{Y}}^{-1}
$$

where $K_{\mathrm{IBE}}=2.14$, as shown above; $E_{\mathrm{Y}}=0.95$ - energy recording efficiency ${ }^{90} \mathrm{Y}$ on KRK-1, set according to 
the technical documentation of the radiometer [8]. In the fourth stage, the calculation of the total counting rate of ${ }^{90} \mathrm{Sr}$ and ${ }^{137} \mathrm{Cs}\left(\mathrm{I}_{\mathrm{SrCs}}\right)$ in the counting sample of the herbal preparation according to the formula:

$$
I_{\mathrm{SrCs}}=\left(\left(I_{\mathrm{imp} / \mathrm{s}}-I_{\mathrm{Y}}\right) \cdot E_{\mathrm{SrCs}}{ }^{-1}\right) \cdot q^{-1}
$$

where $E_{\mathrm{SrCs}}$ - average registration efficiency ${ }^{90} \mathrm{Sr}(0.46)$ and ${ }^{137} \mathrm{Cs}(0.44)$ equal to $0.45 ; q$ is the correction for backscattering of low-energy radiation.

In the fifth stage, the share of ${ }^{137} \mathrm{Cs}$ pulses in the counting speed of the counting sample $\left(I_{\mathrm{Cs}}\right)$ was calculated according to the formula:

$$
I_{\mathrm{Cs}}=I_{\mathrm{SrCs}}-I_{\mathrm{Y}}
$$

The observations showed that the quality of the results of calculating the share of ${ }^{137} \mathrm{Cs}$ pulses will largely depend on the reliability of the measured and calculated pulse fraction ${ }^{90} \mathrm{Y}$, the value of which is attributed to ${ }^{90} \mathrm{Sr}$.

In the sixth stage, the beta radiation activity of ${ }^{90} \mathrm{Sr}$ and ${ }^{137} \mathrm{Cs}\left(A_{r n}, \mathrm{~Bq}\right)$ radionuclides in the preparation was calculated.

$$
A_{r n}, \mathrm{~Bq}=I_{r n} \cdot E_{a r n}
$$

where $r n$ - the radionuclide for which the calculation is performed

At the seventh stage, the concentration of radionuclides in the counting samples of plant origin $\left(A_{r n}, \mathrm{~Bq} / \mathrm{kg}\right)$ was calculated according to the formula:

$$
A_{r n}, \mathrm{~Bq} / \mathrm{kg}=A_{r n} \cdot \mathrm{m}^{-1} \cdot 1000
$$

where $m$ - mass of the preparation, $\mathrm{g}$
Thus, the method of quantitative beta radiometric indication of ${ }^{90} \mathrm{Sr}$ and ${ }^{137} \mathrm{Cs}$ is based on the results of double measurement of a counting sample of plant origin - without filter and with filter. The applied system of mathematical calculations allows to calculate the concentration of ${ }^{90} \mathrm{Y}$ in the counting sample on the basis of the established parameters of radiation protection of the filter, and to assign it to ${ }^{90} \mathrm{Sr}$ which is in radiation equilibrium with ${ }^{90} \mathrm{Y}$. Based on the obtained data - calculate the concentration of ${ }^{137} \mathrm{Cs}$ in the drug minus the fraction of the rate of counting the beta radiation pulses ${ }^{90} \mathrm{Sr}+{ }^{90} \mathrm{Y}$.

\section{3. Estimation of the relative total uncertainty} formed during the quantitative beta-radiometric indication and comparison of the obtained results with the data of beta-spectrometric measurements of ${ }^{90} \mathrm{Sr}$ and ${ }^{137} \mathrm{Cs}$ in counting samples of plant origin

Estimation of the total relative uncertainty of the quantitative indication of beta emitting radionuclides by laboratory radiometry was made on the basis of uncertainties formed during laboratory analysis and radiometric measurement. In the laboratory analysis, uncertainties were related to the drying and weighing of the drugs, which averaged $4.0 \pm 1.0 \%$. In beta radiometric measurements of counting speeds of samples without filter and with filter, the average relative uncertainty was, for example, for 15 samples of plant leaves collected in $2019-4.1 \%$ and $11 \%$ respectively, to which is added $25 \%$ of measurement uncertainty attributed according to technical radiometer instructions.

The relative uncertainty of the ${ }^{90} \mathrm{Sr}$ and ${ }^{137} \mathrm{Cs}$ concentration calculated for the 2017 and 2019 counting samples did not exceed $44 \%$ and $43 \%$, respectively (Table 3).

Table 3

Estimation of uncertainty $(\mathrm{u}, \%)$ at quantitative indication of ${ }^{90} \mathrm{Sr}$ and ${ }^{137} \mathrm{Cs}$ in leaves of plants by a method of laboratory beta radiometry

\begin{tabular}{|c|c|c|c|c|c|c|}
\hline \multirow{2}{*}{ Year } & Type of plants & $\mathrm{n}$ & ${ }^{90} \mathrm{Sr}+{ }^{137} \mathrm{Cs}, \mathrm{Bk} / \mathrm{kg}$ & \multicolumn{3}{|c|}{$\mathrm{u}, \%\left({ }^{90} \mathrm{Sr},{ }^{137} \mathrm{Cs}\right)$} \\
\cline { 5 - 7 } 2017 & $\begin{array}{c}\text { A. Phragmites } \\
\text { B. Pendula } \\
\text { P. Nigra }\end{array}$ & 35 & 38500 & Min & 25 & 27 \\
\hline 2019 & A. Phragmites & 15 & 9000 & 25 & 28 & 44 \\
\hline
\end{tabular}

Note: ${ }^{90} \mathrm{Sr}+{ }^{137} \mathrm{Cs}$ is the median value of the total concentration of radionuclides measured in the respective samples during the specified year

Comparison of measurements of 8 counting samples of reed leaves, performed by quantitative beta radiometric indication and beta spectrometry showed that the median value of ${ }^{90} \mathrm{Sr}$ concentration in plant leaves obtained by beta radiometry is $440 \mathrm{~Bq} / \mathrm{kg}$, by beta spectrometry $-560 \mathrm{~Bq} / \mathrm{kg}$; the same for ${ }^{137} \mathrm{Cs}-4700 \mathrm{~Bq} / \mathrm{kg}$ and $4000 \mathrm{~Bq} / \mathrm{kg}$, respectively.

Comparison of two samples obtained by radiometry and spectrometry using a nonparametric Spearman correlation coefficient showed that the correlation coefficient of ${ }^{90} \mathrm{Sr}$ samples is 0.97 , and ${ }^{137} \mathrm{Cs}$ samples -1 . Comparison of these samples by median equality, type of statistical distribution and coefficient the samples have equal medians, the same type of statistical distribution and do not differ in coefficients of variation.
Thus, statistical analysis by the Monte Carlo method showed that the measurement results obtained by the method of quantitative beta radiometric indication, almost completely correspond to the results obtained by the method of beta spectrometry.

\section{Discussion of research results}

Modern methods of radiometry of beta-emitting radionuclides are based on more sensitive scintillation detectors and involve radiochemical isolation of certain radionuclides from the sample, followed by measurement of the activity of thin counting samples [11]. Beta spectrometry, which also uses highly sensitive scintillation detectors, is based on the registration of continuous beta spectra, which differ from each other in shape and posi- 
tion on the energy scale. The method of energy intervals or windows is used to process the spectra of betaemitting radionuclides [12]. Unlike beta radiometry with chemical release of radionuclides and analysis of a thin counting sample, beta energy spectrometry makes it possible to measure thick counting preparations without prior chemical isolation. Our proposed method is based on the use of a less sensitive gas discharge detector and does not involve the chemical release of radionuclides. The counting rate of beta particles emitted by a thick counting sample is measured. The disadvantage of our proposed method is its lower sensitivity and indirect registration of ${ }^{90} \mathrm{Sr}{ }^{137} \mathrm{Cs}$ by measuring ${ }^{90} \mathrm{Y}$. Compared with highsensitivity beta-radiometry, our proposed method does not require complex laboratory equipment procedures and significant costs. To create a counting sample, it is enough to dry the sample, grind it, take a sample and fill the radiometer cuvette with it. The lower sensitivity of the method is compensated by its expressiveness and reduction of the components of the total uncertainty, which is achieved due to the reduction of the number of analytical procedures in the manufacture of the calculation sample. Similar to beta spectrometry, the method of quantitative indication of radionuclides is also based on the use of an energy interval, but only one for ${ }^{90} \mathrm{Y}$, which is provided by the use of a radiation filter.

Study limitations. Despite the fact that the proposed method is qualitatively significantly inferior to the spectrometry of beta radiation energy, at the same time it is significantly less expensive in terms of the cost of hardware. The method of quantitative indication of beta-emitting radionuclides can be used as an auxiliary in the control of radionuclide contamination and radioecological studies, if necessary, increase the number of measured samples and for special methodological developments.

Prospects for further research. The proposed method of quantitative indication of ${ }^{90} \mathrm{Sr}$ and ${ }^{137} \mathrm{Cs}$, performed by laboratory beta radiometry using a beta radiation energy filter is promising for use in conditions of man-made pollution, when the activity of ${ }^{90} \mathrm{Sr}$ and ${ }^{137} \mathrm{Cs}$ in counting samples is not less than three times higher than the concentration of natural beta. Due to the costeffectiveness, lack of complex preparation of drugs for analysis, expressiveness and high sensitivity of the method, it is also promising in conducting radioecological surveys of areas contaminated with man-made radionuclides, and for developing and improving methods of radioecological indication of the environment.

\section{Conclusions}

1. In plant samples with ChEZ there are 4 beta emitting radionuclides - natural ${ }^{40} \mathrm{~K}$, man-made ${ }^{90} \mathrm{Sr}+$ ${ }^{90} \mathrm{Y}$ and ${ }^{137} \mathrm{Cs}$. In this case, the concentration of ${ }^{40} \mathrm{~K}$ is usually less than $1 \%$ compared to the concentration of man-made radionuclides, so when measuring ${ }^{90} \mathrm{Sr}$ and ${ }^{137} \mathrm{Cs}$ in counting samples of beta radiation ${ }^{40} \mathrm{~K}$ can be neglected. The proposed method of quantitative radiometric indication of beta-emitting radionuclides involves measuring the speed of counting the radiation of counting samples without a filter and using a filter made of fine molybdenum. When measuring the beta particle flux without a filter, the total number of pulses from betaemitting radionuclides in the sample, both low-energy ${ }^{90} \mathrm{Sr}$ and ${ }^{137} \mathrm{Cs}$ and high-energy ${ }^{90} \mathrm{Y}$, is recorded. When using a molybdenum filter, in samples with ChEZ, more than $95 \%$ of ${ }^{90} \mathrm{Y}$ radiation is detected. This makes it possible to determine the activity of ${ }^{90} \mathrm{Y}$ in the counting sample by taking into account the difference in the efficiency of recording pulses from high and low energy radiation.

2. Based on the results of research, a procedure for mathematical calculation of the concentration of ${ }^{90} \mathrm{Sr}$ and ${ }^{137} \mathrm{Cs}$ in counting samples of plant leaves was developed. The applied calculation system allows to calculate the concentration of ${ }^{90} \mathrm{Y}$ in the counting sample on the basis of the established parameters of radiation protection, and to assign it to ${ }^{90} \mathrm{Sr}$, with which ${ }^{90} \mathrm{Y}$ is in a state of radiation equilibrium. Based on the obtained data, the concentration of ${ }^{137} \mathrm{Cs}$ in the drug is calculated minus the fraction of the rate of counting the beta radiation pulses ${ }^{90} \mathrm{Sr}+{ }^{90} \mathrm{Y}$.

3. The total relative uncertainty of the quantitative indication of beta emitting radionuclides by laboratory radiometry consists of uncertainties formed during drying and weighing of drugs, radiometric measurement and due to the radiometer prescribed by the technical documentation. The total relative uncertainty of the measured ${ }^{90} \mathrm{Sr}$ and ${ }^{137} \mathrm{Cs}$ concentrations calculated for the 2017 and 2019 calculation samples did not exceed $44 \%$ and $43 \%$, respectively. Statistical analysis by the Monte Carlo method showed that the measurement results obtained by the method of quantitative beta radiometric indication correspond to the results obtained by the method of beta spectrometry. The proposed measurement method can be used as an aid in the control of radionuclide contamination and radioecological research.

\section{Acknowledgment}

The authors are very grateful to Mr. Leonid Bohdan and Mr. Oleksandr Nazarov (State Specialized Enterprise "Ecocenter") for useful advice and support in this work.

\section{Conflict of interests}

The authors declare that they have no conflicts of interest.

\section{References}

1. Hou, X., Roos, P. (2008). Critical comparison of radiometric and mass spectrometric methods for the determination of radionuclides in environmental, biological and nuclear waste samples. Analytica Chimica Acta, 608 (2), 105-139. doi: http://doi.org/10.1016/j.aca.2007.12.012

2. Maksimov, M. T., Odjagov, G. O. (1989). Radioactive contamination and their measurement. Moscow: Energoatomizdat, 2, 304.

3. Cherniavskyi, Y. Yu., Cherniavskyi, O. Yu., Pysarev, S. A., Halak, A. V. (2015). Accounting of mixed radiation during the measurement radioactive contamination of different subjects in field conditions. Zbirnyk naukovykh prats Kharkivskoho universytetu Povitrianykh Syl, 2 (43), 159-165. 
4. Sahin, S., Kursat, M., Yilmaz, E., Kuluozturk, M. H. (2016). Determination of the gross alpha-beta radioactivity levels in some of medicinal and aromatic plants. Applied Science Reports, 14 (2), 202-206. doi: http://doi.org/10.15192/pscp.asr.2016. 14.2.202206

5. Radiometri kombinirovannie KRK-1. Tekhnicheskoe opisanie i instruktsiia po ekspluatatsii. 1.287.603 TO, 47.

6. Rubinstein, R. Y., Kroese, D. P. (2017). Simulation and the Monte Carlo method. John Wiley \& Sons, 396.

7. Hanzha, D. D., Hanzha, D. D. (2015). The accumulation of radionuclides, potassium, calcium ions in leaves of Phragmites australis (Cav.) Trin. ex Steud. Naukovi zapysky Ternopilskoho natsionalnoho pedahohichnoho universytetu imeni Volodymyra Hnatiuka. Hidroekolohiia, 3/4 (64), 119-122.

8. Ganzha, D. D., Ganzha, D. D., Nazarov, A. B. (2020). The tensile breaking strenght of Phragmites Australis (CAV.) TRIN. EX STEUD. leaves as a chronic irradiation effect. RAP Conference Proceedings, 4, 103-107. doi: http://doi.org/10.37392/rapproc.2019.20

9. Be, M. M., Chiste, V., Dulien, C. et. al. (2004). Table of radionuclides (comments of evaluation). Monographie BIPM-5, Pavillon de Breteuil, 494.

10. Ganzha, C. D., Gudkov, D. I., Ganzha, D. D., Nazarov, A. B. (2020). Accumulation and distribution of radionuclides in higher aquatic plants during the vegetation period. Journal of Environmental Radioactivity, 222, 106361. doi: http://doi.org/10.1016/ j.jenvrad.2020.106361

11. Levchuk, S. (2016). Dovidnyk po osnovnykh metodakh vyznachannia aktyvnosti radionuklidiv. Natsionalnyi universytet bioresursiv i pryrodokorystuvannia Ukrainy. Kyiv, 119.

12. Babenko, V. V., Kazymyrov, A. S., Rudik, A. F. (2001). Beta-spektrometryia prob okruzhaiushchei sredi. Mizhnarodne spivrobitnytstvo v Chornobyli. Kyiv, 477-493.

Received date 12.01.2021

Accepted date 18.02.2021

Published date 31.03.2021

Dmitro Ganzha, PhD, Member of Branch, Ivano-Frankivsk Branch, Ukrainian Geographical Society, Halytska str., 201, Ivano-Frankivsk, Ukraine, 76008

E-mail: gandyber@gmail.com

Dmytro Ganzha, Postgraduate Student, Institute of Hydrobiology of the National Academy of Sciences of Ukraine, Geroiv Stalingrada ave., 12, Kyiv, Ukraine, 04210

E-mail: dgelid@gmail.com

Borys Sploshnoy, Senior Engineer, State Specialized Enterprise "Central Enterprise for Radioactive Waste Management", Kirova str., 52, Chornobyl, Ukraine, 07270

E-mail: sploshnoybr@ukr.net 